\title{
ELABORAÇÃO E CARACTERIZAÇÃO DE FILMES HÍBRIDOS SILOXANO-PMMA PREPARADOS PELO PROCESSO SOL-GEL SOBRE FOLHAS DE FLANDRES: INFLUÊNCIA DO $\mathrm{pH}$ DO SOL ${ }^{1}$
}

\author{
Sandra Raquel Kunst ${ }^{2}$ \\ Caroline Almeida Santos Fraga ${ }^{3}$ \\ Karine Parise ${ }^{3}$ \\ Paloma Bertoli ${ }^{3}$ \\ Gustavo Ludwig 4 \\ Célia de Fraga Malfatti ${ }^{5}$
}

\section{Resumo}

Os materiais híbridos siloxano-PMMA são um sistema constituído por uma rede siliciosa, à qual estão ligadas cadeias de poli(metacrilato de metila) (PMMA) por ligações covalentes ou por interações físicas. A estabilidade e a transparência possibilitam a aplicação desses materiais no recobrimento de embalagens como as folhas de flandres a fim de aumentar à resistência a corrosão e diminuir a fragilidade desses produtos. Neste contexto, o objetivo do presente trabalho é revestir as folhas de flandres com um filme híbrido obtido a partir de um sol constituído pelos precursores alcoóxidos: 3-(trimetoxisililpropil) metacrilato (TMSM), poli(metacrilato de metila) PMMA e tetraetoxisilano (TEOS) variou-se em dois níveis o pH da solução de hidrńlico 11 a 3). Os filmes foram obtidos pelo processo de dip-coating. Os filmes inviuvo unudos foram caracterizados quanto ao comportamento eletroquímico e morfológico. Os resultados mostraram que o filme híbrido siloxano-PMMA obtido em meio mais ácido $(\mathrm{pH}=1)$ apresentou melhor desempenho eletroquímico e valores maiores de espessura de camada.

Palavras-chave: TEOS; Folha de flandres; Corrosão; pH.

\section{ELABORATION AND CHARACTERIZATION OF HYBRID FILMS SILOXANE-PMMA PREPARED BY SOL-GEL PROCESS ON TIN PLATES: INFLUENCE OF THE PH OF SOL Abstract}

The siloxane-PMMA hybrid materials is a system constituted by a siliceous network, which are linked chains of poly (methyl methacrylate) (PMMA) by covalent bonds or by physical interactions. The stability and transparency to enable application of the coating of packaging materials such as tinplate in order to increase corrosion resistance and to decrease the brittleness of these products. In this context, the aim of this work is to coat the tin plates with a hybrid film obtained from a sol consisting of alkoxide precursors: 3 - (trimethoxysilylpropyl) methacrylate (TMSM), poly (methyl methacrylate) PMMA and tetraethoxysilane (TEOS ) were varied at two levels the $\mathrm{pH}$ of the hydrolysis solution ( 1 and 3 ). The films were obtained by dip-coating process. The hybrid films were characterized on the electrochemical behavior and morphology. The results showed that the siloxane-PMMA hybrid film obtained in more acidic medium $(\mathrm{pH}=1)$ showed better electrochemical performance and higher values of coating thickness.

Key words: TEOS; Tin plate; Corrosion; $\mathrm{pH}$.

Contribuição técnica ao $68^{\circ}$ Congresso Anual da ABM - Internacional, 30 de julho a 2 de agosto de 2013, Belo Horizonte, MG, Brasil.

Eng. Química, Doutoranda, LAPEC, PPGEM, UFRGS, Porto Alegre, RS, Brasil.

Graduanda de Eng ${ }^{\circ}$ metalúrgica, LAPEC, PPGEM, UFRGS, Porto Alegre, RS, Brasil.

Eng. Mecânico, Mestrando, LAPEC, PPGEM, UFRGS, Porto Alegre, RS, Brasil.

Eng. Metalúrgica, Prof ${ }^{\circ}$ Doutora , LAPEC, PPGEM, UFRGS, Porto Alegre, RS, Brasil. 


\section{INTRODUÇÃO}

As folhas de flandres, utilizadas no setor de embalagens são formadas a partir de um substrato metálico composto por uma base de aço que foi submetida a um tratamento de superfície, produzindo uma fina camada de $\mathrm{FeSn}_{2}$, uma camada de estanho e uma camada de óxido de estanho. ${ }^{(1)}$ Quando o estanho atua, a corrosão do aço é suprimida e a reação de corrosão resulta na perda de pequenas taxas de estanho, o que não se torna um problema se for considerada uma grande área de revestimento de estanho e uma pequena área catódica (poros). Por outro lado, quando o estanho não pode atuar como barreira protetiva, a relação de área catódica/anódica é grande, o ferro nas áreas do aço exposto se dissolve e a corrosão por pite pode ocorrer, promovendo falhas na embalagem. ${ }^{(2)}$ Atualmente as embalagens utilizam os tratamentos superficiais baseadas no uso de cromatos, pois estes propiciam aos metais uma excelente resistência à corrosão. ${ }^{(3)}$

Os filmes híbridos siloxano-PMMA podem ser aplicados também em revestimentos anti-corrosivos de metais e ligas metálicas, substituindo os cromatos que já são utilizados há muito anos, mas que dependo da espécie (principalmente o $\mathrm{Cr}+6$ ) apresenta alta toxicidade ao homem e ao meio ambiente. ${ }^{(4,5)}$ Além disso, esses revestimentos apresentaram homogeneidade e ausência de trincas, melhorando a resistência à corrosão destes metais e aumentando a dureza da liga de alumínio em $7 \%$ em relação à liga sem revestimento. ${ }^{(6)}$

Embora já tenha sido demonstrado que os filmes híbridos siloxano são relativamente eficientes para a proteção de substratos metálicos contra a corrosão, a eficiência da proteção conferida pela camada depende de parâmetros como o pH da solução, que é considerado o parâmetro responsável pela estabilidade do silano em solução aquosa, e, em última instância, pela vida útil da solução de hidrólise. Este parâmetro controla o comportamento de um determinado silano durante as reações de hidrólise e condensação, já que ambas as reações são catalisadas por ácidos ou bases. ${ }^{(7,8)}$

As reações de hidrólise e condensação em fase aquosa das moléculas de silanol ocorrem simultaneamente na solução de hidrólise. Porém a velocidade de hidrólise de grande parte dos silanos, em soluções aquosas levemente ácidas, é bem mais rápida que a velocidade de condensação. Neste contexto, o objetivo do presente trabalho é elaborar, caracterizar e avaliar a resistência a corrosão das folhas de flandres revestida com um filme híbrido obtido a partir de um sol constituído pelos precursores alcoóxidos: 3-(trimetoxisililpropil)metacrilato (TMSM), poli(metacrilato de metila) PMMA e tetraetoxisilano (TEOS) variando-se em dois níveis o pH da solução de hidrólise (1 e 3).

\section{MATERIAIS E MÉTODOS}

\subsection{Preparação da Superfície}

As folhas de flandres foram lavadas com acetona e secas com ar quente. Posteriormente, foram desengraxados com detergente neutro $(\mathrm{pH}=7)$, à $70^{\circ} \mathrm{C}$ por imersão durante 10 minutos. Em seguida foram lavados com água deionizada e acetona e secos com ar quente. 


\subsection{Elaboração e Aplicação dos Filmes Híbridos Siloxano-PMMA}

A metodologia sol-gel foi empregada na preparação dos materiais híbridos orgânicoinorgânicos. Na preparação da fase inorgânica, foi realizada a síntese dos precursores TEOS e TMSM que foram misturados a $60^{\circ} \mathrm{C}$ por 1 hora. A hidrólise foi efetuada em meio ácido, variando em dois níveis o valor de $\mathrm{pH}(\mathrm{pH}=1$ e $\mathrm{pH}=3)$, utilizando ácido nítrico como catalisador e etanol e água como solventes. A fase orgânica consistiu na homogeneização à temperatura ambiente do MMA, onde o iniciador térmico é o peróxido de benzoíla (BPO). Finalmente as duas soluções (orgânicas e inorgânicas) foram misturadas. Os filmes foram obtidos pelo processo de dip-coating, com velocidade de retirada $14 \mathrm{~cm} . \mathrm{min}^{-1}$. Posteriormente, os substratos revestidos foram tratados termicamente (cura) a uma temperatura próxima de $160^{\circ} \mathrm{C}$ por $3 \mathrm{~h}$ sob uma taxa de aquecimento de $5^{\circ} \mathrm{C} / \mathrm{min}$. A Tabela 1 mostra a descrição das amostras utilizadas.

Tabela 1. Descrição das amostras utilizadas

\begin{tabular}{c|c}
\hline Amostra & Descrição \\
\hline FI & Folha de flandres sem revestimento. \\
\hline FIN1 & $\begin{array}{r}\text { Folha de flandres revestida c/ filme híbrido siloxano-PMMA } \\
\text { acidificada com ácido nítrico e } \mathrm{pH}=1 \text { de TEOS. }\end{array}$ \\
\hline FIN3 & $\begin{array}{r}\text { Folha de flandres revestida c/ filme híbrido siloxano-PMMA } \\
\text { acidificada com ácido nítrico e } \mathrm{pH}=3\end{array}$ \\
\hline
\end{tabular}

\subsection{Caracterização dos Filmes Híbridos Siloxano-PMMA}

Os filmes obtidos foram caracterizados quanto à morfologia por MEV, em um equipamento JEOL-JSM 5800 do centro de microscopia eletrônica da UFRGS, com tensão de aceleração 20 keV.

O ângulo de contato foi realizado pelo método da gota séssil a partir de um aparato desenvolvido pelo Laboratório Pesquisa em Corrosão (LAPEC) da Universidade Federal do Rio Grande do Sul. O ângulo de contato foi determinado por meio de um programa de análise de imagens.

O valor do ângulo de contato pelo método da gota séssil de uma gota de líquido depende da energia de superfície da amostra e a tensão superficial do líquido, se a gota se esparramar por toda superfície do material seu ângulo de contato será de aproximadamente zero, mas se o espalhamento for parcial o ângulo de contato variará de 0 a $180^{\circ}$. O líquido selecionado determina o grau de molhabilidade e de interação com a superfície do substrato. Este líquido deve reunir as seguintes propriedades: baixa volatilidade, baixa viscosidade, ser estável e não atacar ou reagir com a superfície do substrato quando o ângulo de contato formado entre o líquido e o sólido é menor do que $90^{\circ}$. $^{(9)}$

Os filmes de silano apresentam caráter hidrofóbico quando são suficientemente reticulados (cross-linking). Dessa forma, o ângulo de contato de um filme bem reticulado é da ordem de aproximadamente $90^{\circ}$. Entretanto, este valor torna-se menor após a imersão em uma solução aquosa, o que indica que os grupos Si-O-Si não são estáveis. Então, devido ao fato dessas ligações não serem estáveis, os grupos Si-O-Si podem sofrer reações de hidrólise, formando novamente os grupos Si-OH hidrofílicos de tal forma que a água e os íons podem penetrar e reagir com a interface. Consequentemente, os filmes de silano protegem os metais temporariamente, até mesmo os filmes mais hidrofóbicos, pois as propriedades de 
adesão e barreira podem variar com o tempo de exposição ao ar ou exposição aquosa, devido à susceptibilidade das ligações Si-O-Si sofrem reações de hidrólise. ${ }^{(10)}$

Para as medidas de impedância eletroquímica foi utilizado um potenciostato (Omnimetra Mod. PG-05) acoplado a um analisador de reposta em frequência (Solartron 1255). As medidas foram realizadas aplicando-se um sinal senoidal de $10 \mathrm{mV}$ e varredura de $100 \mathrm{kHz}$ a $10 \mathrm{mHz}$. Utilizou-se $10 \mathrm{mV}$ RMS de amplitude. O eletrólito utilizado foi uma solução de $\mathrm{NaCl}$ na concentração de $0,05 \mathrm{M}$. O monitoramento do potencial de circuito aberto durante a primeira hora de imersão e as curvas de polarização potenciodinâmicas foram obtidas utilizando-se para isso um potenciostado PAR 273. As curvas de polarização foram obtidas com velocidades de varredura de $1 \mathrm{mV} / \mathrm{s}$ em uma faixa de potencial de $200 \mathrm{mV}$ (abaixo do potencial de circuito aberto) até $400 \mathrm{mV}$ (acima do potencial de circuito aberto).

\section{RESULTADOS}

\subsection{Caracterização Morfológica}

A Figura 1 apresenta as micrografias obtidas por MEV para as amostras estudadas FIN1 $(\mathrm{pH}=1)$ e FIN3 $(\mathrm{pH}=3)$.
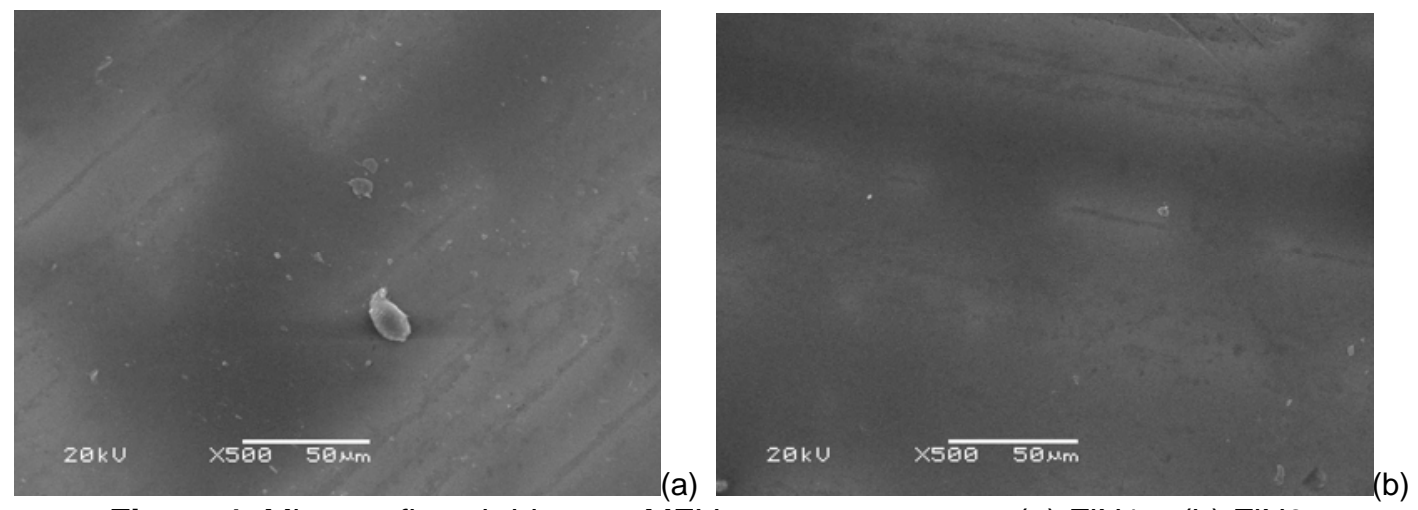

Figura 1. Micrografias obtidas por MEV para as amostras: (a) FIN1 e (b) FIN3.

A espessura de camada dos filmes por determinada por análise de imagens obtidas por MEV da secção transversal (Figura 2) e os resultados estão apresentados na Tabela 1.
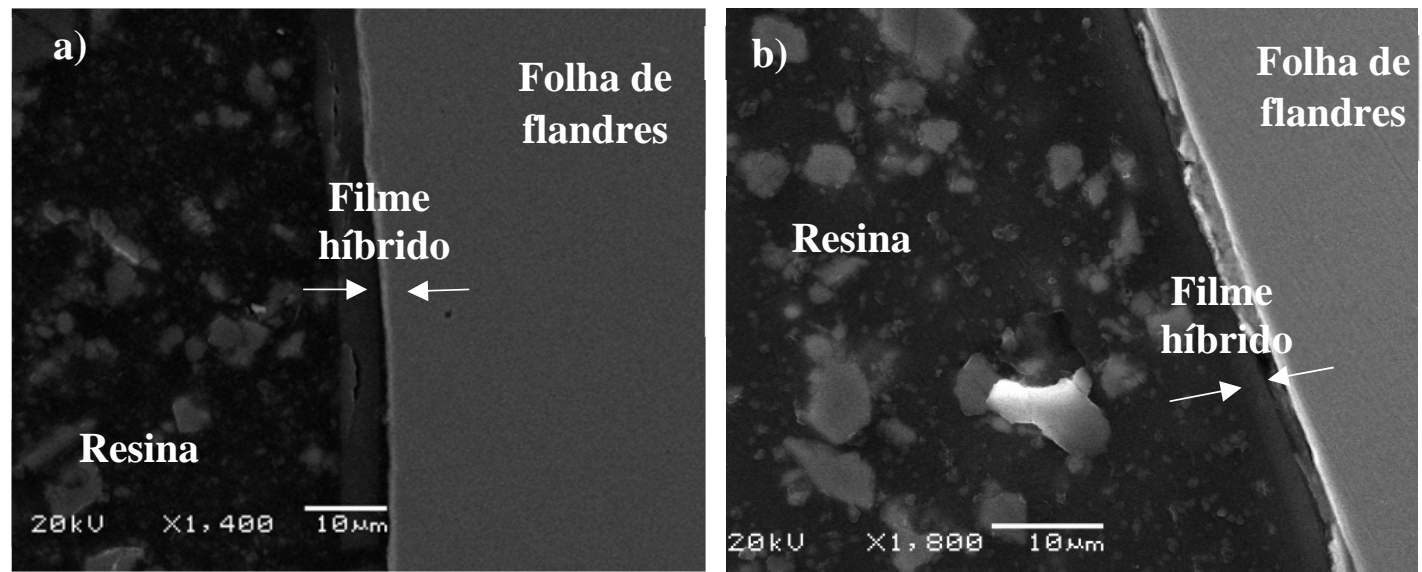

Figura 2. Micrografias obtidas por MEV com corte transversal para a determinação da espessura de camada para as amostras: (a) FIN1 e (b) FIN3. 
Tabela 2. Espessura de camada dos revestimentos obtidos

\begin{tabular}{c|c|c}
\hline Amostra & Espessura $(\boldsymbol{\mu m})$ & Desvio Padrão $(\boldsymbol{\mu m})$ \\
\hline FIN1 & 6,00 & 0,45 \\
\hline FIN3 & 2,30 & 0,29 \\
\hline
\end{tabular}

A Figura 3 mostra as imagens obtidas para a determinação do ângulo de contato pelo método da gota séssil. A partir da Tabela 2 é possível observar as medidas de ângulo de contato obtidas para os sistemas estudados.

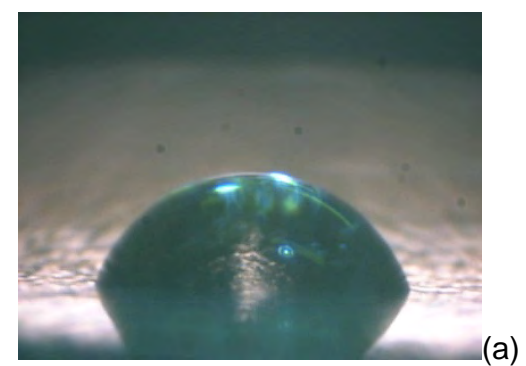

Figura 3. Imagens obtidas para determinação do ângulo de contato:

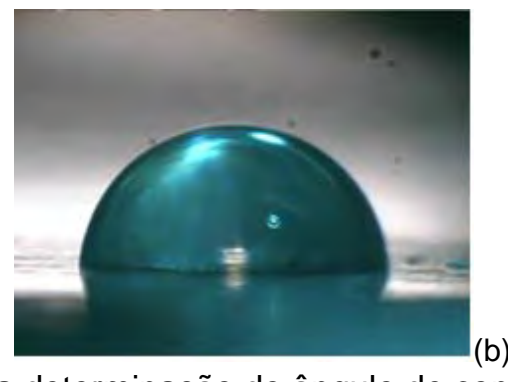

(b)

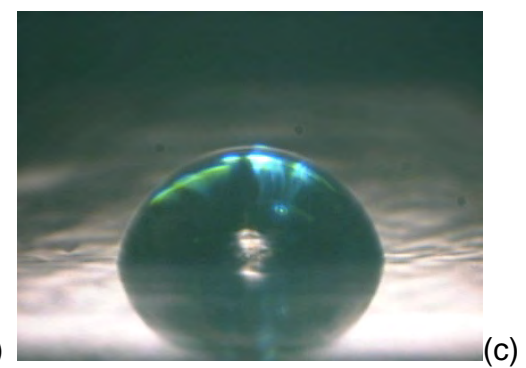

(a) FI, (b) FIN1 e (c) FIN3.

Tabela 3. Ângulo de contato médio e desvio padrão obtidos

\begin{tabular}{c|c}
\hline Amostra & Valor \\
\hline Fl & $79^{\circ} \pm 0,44$ \\
\hline FIN1 & $94^{\circ} \pm 0,93$ \\
\hline FIN3 & $81^{\circ} \pm 1,34$ \\
\hline
\end{tabular}

\subsection{Caracterização Eletroquímica}

\subsubsection{Potencial de circuito aberto e curvas de polarização}

Foram realizadas medidas de potencial de circuito aberto a fim de monitorar a variação do potencial com o tempo de imersão (Figura 4a). A partir da extrapolação das retas de Tafel, aplicada às curvas de polarização apresentadas na Figura 4b, foram determinados o potencial de corrosão (Ecorr), a densidade de corrente de corrosão (icorr) e a resistência de polarização (Rp) para todos os sistemas estudados (Tabela 3).
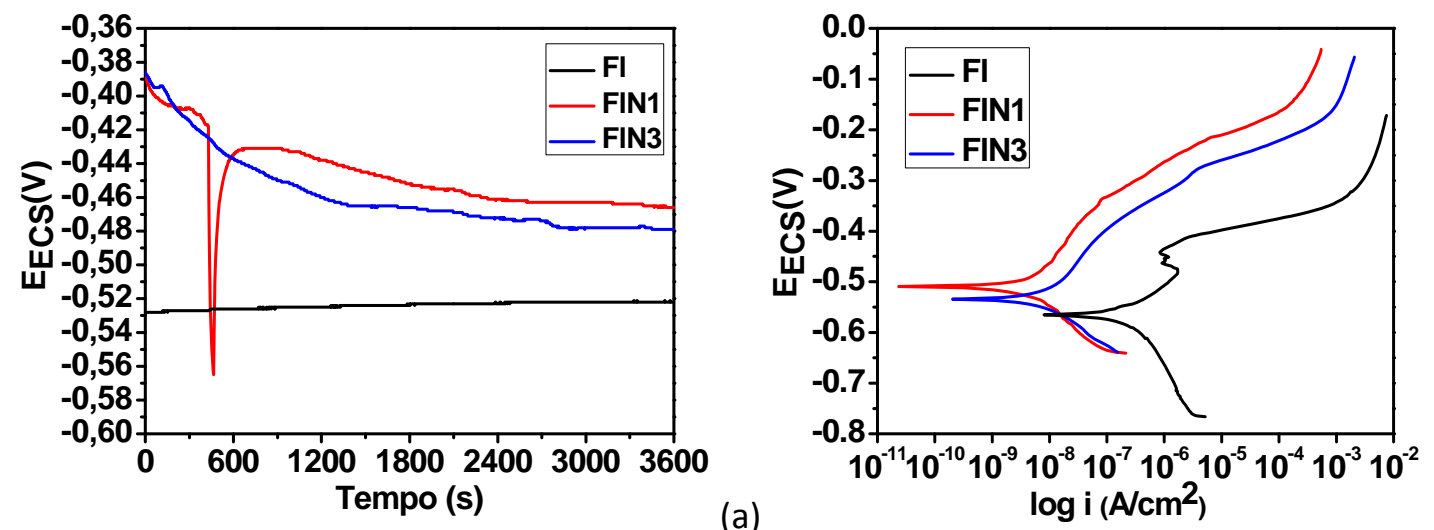

(a)

Figura 4. Gráficos: (a) medida de potencial de circuito aberto e (b) curvas de polarização obtidas para todas as amostras estudadas e a folha de flandres sem revestimento. 
$68^{\text {th }}$ abm international annual congress

Tabela 4. Dados obtidos partir da extrapolação das retas de Tafel

\begin{tabular}{c|c|c|c} 
Amostras & $\mathbf{i}_{\text {corr }}\left(\mathbf{A} / \mathbf{c m}^{2}\right)$ & $\mathbf{E}_{\text {corr }}(\mathbf{m V})$ & $\mathbf{R p}(\mathbf{\Omega})$ \\
\hline FI & $4,71 \times 10^{-7}$ & -568 & $5,54 \times 10^{4}$ \\
\hline FIN1 & $2,96 \times 10^{-8}$ & -502 & $1,13 \times 10^{6}$ \\
\hline FIN3 & $1,41 \times 10^{-7}$ & -539 & $1,85 \times 10^{5}$ \\
\hline
\end{tabular}

\subsubsection{Espectroscopia de impedância eletroquímica}

$\mathrm{Na}$ Figura 5 são apresentadas os diagramas de Nyquist e Bode para os filmes híbridos FIN1, FIN3 e folha de flandres sem revestimento nos tempos de imersão de 24 e $96 \mathrm{~h}$ em $\mathrm{NaCl} 0,05 \mathrm{M}$.
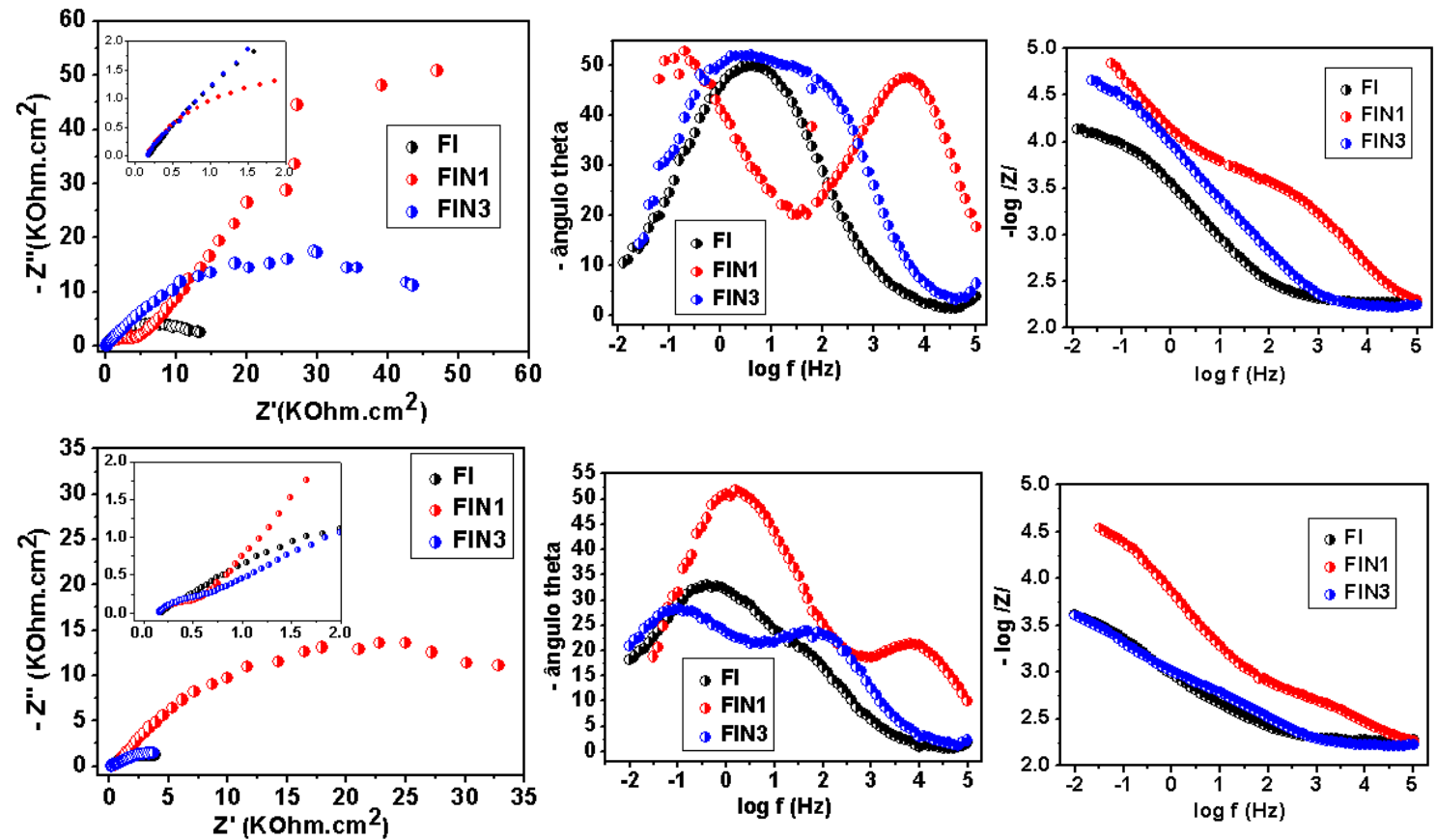

(a)

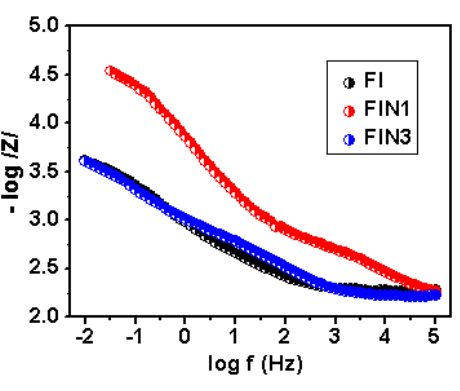

(b)

Figura 5. Diagramas de Nyquist e Bode obtidos para todas as amostras estudadas e para folhas de flandres sem revestimento em solução de $\mathrm{NaCl}$ 0,05M: (a) 24h e (b) $96 \mathrm{~h}$.

A Figura 6 apresenta as imagens obtidas após 96h de ensaio de impedância eletroquímica em solução de $\mathrm{NaCl}$ 0,05M.
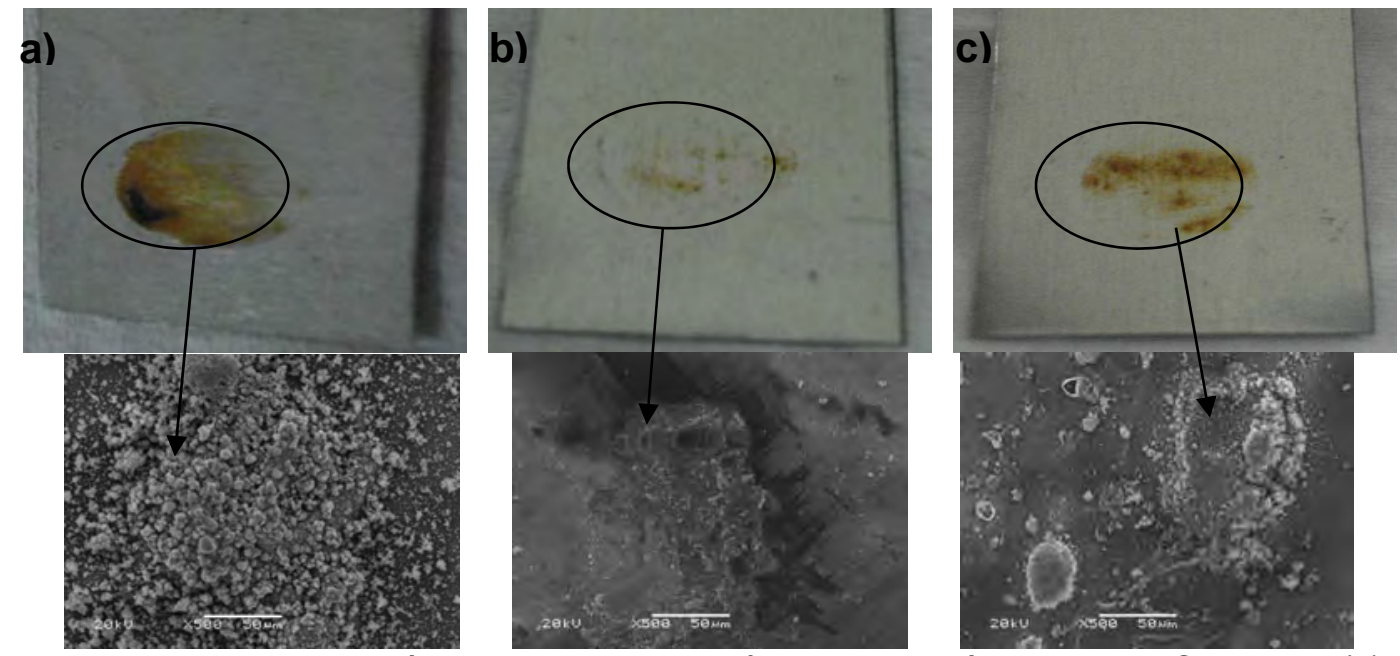

Figura 6. Imagens obtidas após 96horas de impedância eletroquímica em $\mathrm{NaCl} 0,05 \mathrm{M}$ : (a) $\mathrm{FI}$, (b) FIN1 e (c) FIN3. 


\section{DISCUSSÕES}

O aspecto morfológico obtido é de um filme homogêneo e sem fissuras, apresentando pequenas descontinuidades nas duas amostras estudadas: FIN1 (Figura 1a) e FIN3 (Figura 1b). Isso denota a excelente interação entre as fases orgânica e inorgânica dos filmes híbridos siloxano-PMMA. Propriedades como flexibilidade e aderência foram alcançadas pelo filme devido a correta proporção de PMMA no sistema siloxano-PMMA evitando a formação de fissuras e desplacamento.

Nos resultados de determinação de espessura de camada dos filmes híbridos, observa-se que para o filme híbrido siloxano-PMMA mais ácido, FIN1 ( $\mathrm{pH}=1)$, apresentou maior valor de espessura de camada quando comparado ao filme híbrido menos ácido, FIN3 ( $\mathrm{pH}=3$ ). Isso está de acordo conforme reportado na literatura, o pH mais ácido da solução tem a máxima velocidade de hidrólise das moléculas de silano e a mínima velocidade de condensação das moléculas de silano já hidrolisadas (silanol) em solução, auxiliando numa maior formação de grupos siloxanos responsáveis pela formação da camada barreira e aumento de espessura do filme melhorando, consequentemente, o desempenho anticorrosivo. ${ }^{(8)}$

Pela análise dos testes de molhabilidade pode-se observar que a amostra mais ácida, FIN1, foi a que apresentou maior valor de ângulo de contato, e consequentemente a menor molhabilidade. Este comportamento está associado à formação de mais grupos siloxanos no sistema mais ácido (FIN1), formando uma rede tridimensional mais compacta impedindo a absorção da água, tornando o filme mais hidrofóbico. O alto valor de ângulo de contato obtido para o Fl está associado ao fato que a folha de flandres apresenta na superfície uma cobertura completa ou parcial de óxidos de estanho $\left(\mathrm{SnO}_{\mathrm{x}}\right)$, a qual pode conter óxido estanoso ( $\mathrm{SnO}$ ) ou óxido estânico $\left(\mathrm{SnO}_{2}\right)$, incluindo suas formas hidratadas aumentado o grau de hidrofobicidade. ${ }^{(11)}$

Analisando-se os valores de potencial de circuito aberto (Figura 4a) para os filmes híbridos estudados (FIN1 e FIN3) foi possível observar que esses sistemas apresentaram valores de potenciais deslocados no sentido de potenciais menos ativos em relação à folha de flandres sem revestimento (FI). Ou seja, os revestimentos híbridos obtidos promoveram a formação de uma barreira entre o substrato e o meio. Os resultados obtidos a partir do ensaio de polarização (Figura 4b e Tabela 3) mostraram que os filmes híbridos siloxano-PMMA promoveram o aumento da resistência de polarização $(R p)$ e a diminuição do icorr, comparativamente a folha de flandres não revestida, evidenciando a ação protetora desses revestimentos.

Entretanto, foi possível observar que a amostra mais ácida $(\mathrm{pH}=1)$, ou seja, FIN1 apresentou um melhor desempenho na resistência à corrosão que a amostra menos ácida $(\mathrm{pH}=3)$. Conforme visto anteriormente, este resultado indica que o $\mathrm{pH}$ ácido da solução auxiliou na formação de mais grupos siloxanos responsáveis pelo aumento da espessura do filme (Figura 2 e Tabela 2).

Pelos diagramas de Nyquist (Figura 5) é possível observar que entre as amostras estudadas, a que apresentou maiores valores de resistência em todos os tempos analisados (até 96h de imersão) foi o filme híbrido siloxano-PMMA FIN1 ( $\mathrm{pH}=1$ ). Esse resultado indica que conforme analisado nas curvas de polarização (Figura $4 \mathrm{~b}$ e Tabela 3) que o pH mais ácido auxiliou na formação da camada barreira, promovendo o aumento da espessura do filme (Figura 2 e Tabela 2Erro! Fonte de 
referência não encontrada.), tornando o filme mais hidrofóbico (Figura 3 e Tabela 3) e melhorando consequentemente, o desempenho anticorrosivo.

Pelos diagramas de Bode (Figura 5) observou-se em todo o tempo de imersão um fenômeno em alta frequência associado ao efeito barreira do filme híbrido siloxanoPMMA apenas para a amostra FIN1. Isto mostra o efeito protetivo desse revestimento quanto à resistência à corrosão, conforme observado nas imagens após ensaio eletroquímico (Figura 6b) e os altos valores de módulo de impedância obtidos para esse filme.

Para a amostra FIN3 ( $\mathrm{pH}=3$ ), observou-se apenas o fenômeno em média frequência associado a permeabilidade do eletrólito atráves do filme híbrido, este baixo desempenho anticorrosivo está associado ao fato desse filme apresentar uma menor velocidade de hidrólise das moléculas de silano, diminuindo o número de grupos silanóis e consequentemente obtendo menor formação de grupos siloxanos prejudicando na formação da camada barreira desse filme o que pode ser evidenciado no baixo valor de espessura de camada obtida (Figura 2 e Tabela 1).

Em relação a folha de flandres sem revestimento observa-se em $24 \mathrm{~h}$ de imersão (Figura 5a) apenas uma constante de tempo associada à permeabilidade do eletrólito nos óxidos de estanho na superfície da folha de flandres. Em 96h de imersão (Figura 5b), observam-se duas constantes de tempo e uma em média frequência possivelmente associada à permeabilidade do eletrólito nos óxidos de estanho na superfície da folha de flandres e uma constante em baixa freqüência associado ao produto de corrosão do ferro conforme observado nas imagens após ensaio eletroquímico (Figura 6a).

Pelas imagens obtidas após $96 \mathrm{~h}$ do ensaio de impedância eletroquímica foi possível observar que a amostra FIN1 (Figura 6b) apresentou menos produto de corrosão o que justifica o melhor desempenho desse filme híbrido nos ensaios eletroquímicos.

\section{CONCLUSÕES}

Os resultados mostraram a amostra obtida em meio mais ácido $(\mathrm{pH}=1)$ apresentou um melhor desempenho eletroquímico e valores maiores de espessura de camada. Esse comportamento está associado à formação de mais grupos siloxanos no sistema mais ácido (FIN1), formando uma rede tridimensional mais compacta impedindo a absorção da água, tornando o filme mais hidrofóbico, responsáveis pela formação da camada barreira, aumento da espessura do filme e melhorando conseqüentemente, o desempenho anticorrosivo.

\section{Agradecimentos}

O presente trabalho foi realizado com o apoio da CAPES, entidade do Governo Brasileiro, voltada para a formação de recursos humanos. Os autores agradecem também o apoio financeiro do CNPq e da FAPERGS.

\section{REFERÊNCIAS}

1 DANTAS, S.T.; ANJOS, V.D.A., SEGANTINI, E. GATTI, J.A.B. Avaliação da qualidade de embalagens Metálicas: Aço e Alumínio. CETEA/ITAL, Campinas, 1996.

2 CALDERÓN J. A.; BUITRAGO C. Evaluación de la susceptibilidad a la corrosión de recipientes de hojalata em diferentes soluciones usando técnicas eletroquímicas. Rev. Fac. Ing. Univ. Antioquia, no.42, p.30-37, Diciembre, 2007 
3 CABRAL A.M., TRABELSI W. SERRA R., MONTEMOR M.F., ZUHELUDKEYICH M.L., FERREIRA M.G.S.. The corrosion resistance of hot dip galvanized steel and AA2024-T3 pre-treated with bis-[triethoxysilylpropyl]tetrasulfide solutions doped with $\mathrm{Ce}(\mathrm{NO} 3) 3$. Corrosion Science, v. 48, p. 3740-3758, 2006.

4 LANGROUDI A. E., GHARAZI S., RAHIMI A., GHASEMI D. Synthesis and morphological study on the nanocomposite hydrophilic coatings. Applied Surface Science, v. 255, p. 5746-5754, 2009.

5 KOZHUKHAROV S., KOZHUKHAROV V., SCHEM M., ASLAN M., WITTMAR M., WITTMAR A., VEITH M. Protective ability of hybrid nano-composite coatings with cerium sulphate as inhibitor against corrosion of AA 2024 aluminium alloy. Progress in Organic Coatings, v. 73, p. 95-103, 2012.

6 ONO S., TSUGE H., NISHI Y., HIRANO S.I. Improvement of corrosion resistance of metals by an environmentally friendly silica coating method. Journal of Sol-gel Science and Thecnology, v. 29, p. 147-153, 2004.

7 OOIJ W. J. V., CHILD T. F. Chemtech, p. 26-35, 1998.

8 OOIJ W. J. V., CHILD T. F. American Chemical Society, p. 354-377, 1999

9 BUZETO F.A., CAMPO J.S.C. Modificação do ângulo de contato de amostras de borracha natural submetida a tratamento por descarga corona. Congresso Conamet/SAM 2009.

10 FLIZ J. KANOZA M. Electrochemical and surface analytical study of vinyl-triethoxy silane films on iron after exposure to air. Electrochimica Acta 51 (2006) 2338-2345.

11 GATTI J. Aderência de vernizes em folhas de flandres. Boletim de tecnologia e desenvolvimento de embalagens, ISSN 0104-3781, v. 20, 2008 